У, $\triangle \mathrm{K} 316.75$

ББК 60.563 .0

DOI 10.22394/1682-2358-2021-3-62-69

V.N. Yarskaya, Doctor of Sciences (Philosopby), Professor, Director of the Scientific and Educational Regional Center for Monitoring Research, Yuri Gagarin State Technical University of Saratov

N.S. Bozbok, Candidate of Sciences (Sociology), Docent of the Philosophy, Sociology, Psychology Department, Yuri Gagarin State Technical University of Saratov

\section{METHODOLOGY OF SOCIOLOGICAL INSTRUMENTATION IN MODERN CULTURAL STUDIES
(Problem Statement)}

The instrumentalism of sociology in the system of cultural studies as a scientific method on the example of the development of the culture of reconstructivism is considered. Cultural studies are presented as a direction accumulating the instrumental experience of sociology. Interdisciplinarity as a principle of scientific methodology assimilates the experience of various intellectual movements, problematization of the value content and social functions of culture, its diverse phenomena. The new possibilities of developing the culturological concept of temporalism are revealed.

Key words and word-combinations: methodology, instrumentalities, cultural studies, cultural and historical reconstruction, temporalism.
В.Н. Ярская, доктор философских наук, профессор, директор Научно-образовательного регионального иентра мониторинговых исследований Саратовского государственного технического университета имени Гагарина Ю.А. (етаil: jarskaja@mail.ru)

Н.С. Божок, кандидат сочиологиеских наук, дочент кафедри философии, сочиологии, психологии Саратовского государственного технического университета имени Гагарина Ю.А. (email:nikolaybozhok@mail.com)

\section{MЕТОАОАОГИЯ СОЦИОАОГИЧЕСКОЙ ИНСТРУМЕНТААЬНОСТИ В СОВРЕМЕННОЙ КУАЬТУРОАОГИИ (постановка проблемы)*}

Аннотация. Рассматривается инструментализм социологии в системе культурологии как научный метод на примере развития культуры реконструктивизма. Культурология представлена в качестве направления, аккумулировавшего также инструментальный опыт социологии. Раскрываются новые возможности разработки культурологической концепции темпорализма.

Ключевые слова и словосочетания: методология, инструментальность, культурология, культурно-историческая реконструкция, темпорализм.

$\mathrm{H}$

1 аука есть ценность культуры, результат институциацьной конструиру* Статья подготовлена при финансовой подАержке РНФ, грант № 18-18-0032-П. 
ющей деятельности, она не только совокупность знаний в понятийной форме, концепций, но и материнское моно методологии как системы принџипов и совокупности методов. Так, методологический горизонт темпорализма раздвинулся благодаря прогностической рефлексии эпохи, которая вышла из презентивых замкнутых циклов и стала существенно оценочной [1, с. 16-20].

Анализ культуры соџиальных групп, этнокультур, национальностей, конфессий, происхождения культуры, мифологии, семантики и эпистемологии, языковых, урбанистических и темпоральных различий народов и

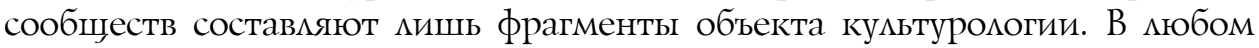
случае, однако, традиционно мы в полном согласии наблюдаем, что Аля высокого уровня научных исследований и теорий, а, как следствие, тематики серьезных публикаций и проводимых научных конференций необходимо четкое следование как минимум трем взаимосвязанным принципам метоАологии науки - межАисциплинарности, межАународности, инструментальности. Если первые два, как говорится, на зубах навязци, то инструментализм, идеологически связанный с прагматизмом, операционализмом

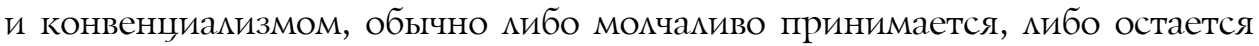
за кадром. Методология науки погружена в культуру, соответствует эпохе, вспоминает и проџеживает прошиое, одновременно заглядывая в будущее, Аействуя в настоящем, то есть распространяется на все модусы времени, оставаясь атемпорацьной.

При этом вопрос методологии гуманитарного знания вообще и роли в ней соџиологической науки, в частности, остается недостаточно исследованным. ОАнако именно инструментальность гуманитарных наук вообще и культурологии, в частности, проявцяется как способ эмпирического анаииза вполне открыто, хотя и не всегда озвучивается откровенно, не освещается как важнейшая тенденция исторического развития, конкретных этапов и механизмов. Инструментализм социологии в системе культуромогии направлен как метоА, применяющий научные понятия, теории и гипотезы социологии в качестве инструментов ориентации и взаимодействия теорий, образов, эмпирических феноменов кумьтуры с сообществами, группами и соџиальными субъектами.

Известно, что американское рождение во второй половине XX в. нового научного направления культурологии (culturology) связано с именем

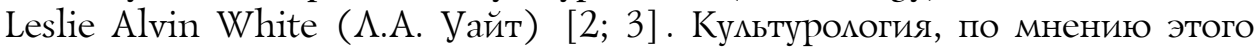
ученого, получившего профессора Чикагского университета, рассматривает культуру и ее технологии, идеологии как упорядоченность феноменов, организованных в соответствии с принципами и законами. Это наука, изучающая культуру как соџиально-историческое явление от возникновения до современности, претендуя на систематизацию знаний о культуре в истории стран и народов $[4$, с. 582,586$]$.

Последовавшая затем Бирмингемская ветвь Cultural studies [5] от- 
четливо и непосредственно опиралась на соџиологию [6], а культурные исследования, в свою очередь, оказали существенное вцияние на социомогию. В Открытом университете Великобритании принимали престижную профессуру соџиологов, а исслеАования культурной соџиологии, как оказалось, стали Аисщиплинарным пристанищем Аля многих практиков в области культурологии. С необходимостью и сегодня существует раздел социологии культуры.

Разумеется, есть и обязательные разиичия межАу соџиологией и культурологией как Аисциплинами в целом. В то время как соџиология создавалась в недрах и под влиянием классической научной картины мира и была основана на разцичных исторических работах, целенаправценно отАеляющих предмет от философии или психологии, культурология открыто подвергла сомнению и критике традиционное понимание и практику Аисџипиинарности, хотя сеГоАня большинство культурологов Продвигают своего рода радикальную межАисциплинарность как основу культурных исследований [7].

ОАин из знаменитых соџиологов оказал большое влияние на исследования культуры, это Пьер Бурдье, который в своих работах напрямую привлекает социологию как инструмент, новаторски используя статистику и глубинные интервью [8]. Несмотря на его авторитетные суждения, культурологические исследователи никогда не принимали идею стремления к научности как основе культурных изысканий. Вполне критически, например, относятся к культурологическим исследованиям R. Chris и В. Turner, утверждая, что культурологические исследования не имеют устойчивой исследовательской программы и отАают преАпочтение современному чтению текстов. Так создается антиисторический теоретический фокус [7], критика Аисциплинарности, неправицьное понимание того, что текстуацьный анациз является еАинственной методологией культурных исследований.

Сегодня культурология - это область теоретического, соџиально-политического и эмпирического анациза культуры, который концентрируется на ее исторических основах, определении специфики, темпоральности феноменов и субъектов. Это междисциплинарное направление, аккумумировавшее в том числе инструментальный опыт соџиологии, разцичных интелмектуальных Авижений, проблематизации ценностного содержания, соџиальных функций культуры и ее многообразных феноменов. Вместе с тем культурология вкцючает в себя не только понятия, структуру, методы и типологию, закономерности развития самых разцичных и отдельных культур, но и социологию культуры вообще как универсальной категории.

ОАним из культурных феноменов, Аинамично развивающихся и помучивших широкое распространение в российском обществе, выступает культурно-историческая реконструкция. Историографическая ситуация в сфере изучения феномена культурно-исторической реконструкции в Рос-

64 Bulletin of the Volga Region Institute of Administration • 2021. Vol. 21. № 3 
сии и зарубежных странах нашла разнообразное и широкое освещение в научной митературе [9-11] . В работах А.С. Ахиезера представлено последовательное, системное описание соџиокультурных механизмов динамики российского общества, его изменения, особенности связей межАу обществом и культурой в проџессе исторического развития [12]. Проблемы реконструкции как предмета и целостного процеса познания исторического прошиого основательно исследуются А.С. Уйбо и Э.Н. Аооне [13; 14]. Аксиологические аспекты процесса реконструкции исторического прошлого детально проанализированы В.А. Аавыдовым [15] .

История науки и научной практики свидетельствует, что ни оАно из исследовательских направлений или разновидностей, форм существования культур не обойдется без привлечения соџиологических инструментов. В структуре культурологического знания шаг за шагом конкретизируется предмет культурологии, а само исследование, в свою очередь, составляет несколько методологических уровней: выбор и синтез методологий, выбор социальных теорий [16] и теорий культуры, семантико-лингвистический анациз, выбор методологии эмпирического исследования. При этом суперпозиџия содержательных объектов методологии, соџиологической теории, объясняющей проблемное поле, Аает пересечение авторской методологии с привлекаемой теорией культур или полевыми требованиями анализа. ГАубинные принципы, общечеловеческие ценности выступают регулятором социализации теории культуры и экзистенџиальным каналом трансмяџии самой культурной парадигмы.

ОАновременно проблематика науки опирается на междисципиинарные исследования, и ранее философская, а сегодня именно соџиологическая методология осуществляет задачу их интеграции. Это Аополнительная поААержкка нашего тезиса о соџиологии как инструменте в эмпирических подвигах культурологии. Важно вовремя привлечь методологию, подходы к обсуждаемой проблеме, научиться плавать в полипарадигмальном море. В противном случае мы останемся с текстами культуры, не понимая, как становятся детерминантами поведения субъектов куцьтур (помимо регумятивных действий институтов власти и субъектов общественного вцияния) право, ценности, стереотипы и в целом гражданская культура.

В эпоху постмодерна трансформация культурно-исторической реконструкции, ориентированной на внеакадемическую аудиторию, сопровождается активным внедрением в нее особенностей массовой кумьтуры. В этом контексте она выполняет одну из наиболее значимых функций современной массовой культуры попуцяризаџии научных знаний о культурно-историческом прошлом, переводя специализированные знания на Аоступный обыденный язык [17, с. 392-393]. Тем самым культурно-историческая реконструкция оказывает существенное вмияние на формирование исторического сознания и патриотической культуры постсоветского поколения россиян, содействуя формированию их сплоченности. Но необходимо 
признать, что Аинамика практики культурно-исторической реконструкщии пока опережкает теоретико-методологические возможности ее научной рефлексии, требуя уточнения концептуального аппарата и методологии.

Кумьтурология более четко систематизирует исторические и гуманитарные знания, явления общественной жизни в едином смысловом контексте. В новой эпистемологической ситуации в результате когнитивных поворотов рубежа XX-XXI вв. (антропологического, прагматического, пространственного, культурного, исторического, визуацьного, материального, рефцексивного) осуществляется активный поиск новых перспектив осмысления исторического и культурного прошиого. Эмпирически выявлено возрастание инкцюзивного потенциала практик культурно-исторической реконструкции в результате интерактивного взаимодействия вовлеченных социальных акторов. Аналитика культурных практик исторической реконструкции показывает, что тенденџия сближения объединений ре-

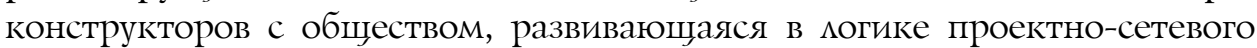
взаимодействия, приобрела устойчивый характер.

Сегодня получияа отражение культурологическая конџепџия, объединяющая теоретико-методологические, историко-культурные и приклаАные основания осмысления прошиого, раскрывающая его специфику как реконструированного феномена, детерминированного настоящим и «работающим» на решение его проблем [18; 19]. Особое внимание уделяется реализации межАисциплинарных подходов к исслеАованию реконструктивного характера культурно-исторической памяти и воссоздаваемого образа прошиого, и здесь набцюдается вторжение в проблему времени со всеми присущими ему моАусами.

Субкультурный подхоА, сложившийся в теоретических традиџиях соџиального конструктивизма и постструктурацизма, в работах отечественных исследователей, имеет несколыко ракурсов исследования, значимых Аля понимания специфики исторической реконструкции. Это прежде всего историческая реконструкщия, интерпретируемая как маргинальная субкультура, существующая в качестве культурологического хобби «на инте мектуацьной окраине» Аоминантной культуры [20], но не антагонистичная ей. Во-вторых, это историческая реконструкция, проблематизируемая как молодежная субкультура, явцяющаяся подсистемой общей культуры, находящаяся в диалоге с официальной культурой и воспринимающая важнейшие гуманистические ценности [21;22].

Наконец, субкультура реконструкторов рассматривается в контексте культурной сложкности современного мира как комлективность, обладающая мощным трансформационным потенциалом, которая благодаря накопиенному общественно-политическому капиталу становится инструментом общественных перемен. В рамках этого направления анацизируются современные процессы трансформации субкультурных реконструкторских сообществ в общественное Авижение, обретающее влиятельные позиџии

66 Bulletin of the Volga Region Institute of Administration • 2021. Vol. 21. № 3 
в социуме [23, с. 14-15]. Эти качественные изменения демонстрируют смену научной оптики в исследовании изучаемого феномена.

Проблемную ситуацию создает недооценка некоторыми государственными структурами научного, культуротворческого и воспитательного потенциала Авижения исторической реконструкции, инструментальное использование успехов его участников Аля достижения наибольшей массовости мероприятий, направленных на репрезентацию официальной версии исторического прошиого. Тем не менее можно отметить преобцаАание рефлексии феномена исторической реконструкции как соџиально ориентированного движения. Предпринимаются попытки периодизаџии отечественного Авижения мюбителей исторической реконструкщии на основе выявления этапов различных форм и видов практик, выражающих общественный интерес к истории и прошлым культурам [24]. В отдемьных статьях рассматриваются также организационные формы движения исторической реконструкции [25] .

Социокультурная гетерогенность Авижения исторической реконструкции, обусловменная отмеченными факторами, при этом часто интерпретируется исследователями как вызов его устойчивой комлективной идентичности и спиоченности $[26 ; 27]$. РяА исследователей обращается к изучению исторической реконструкции как форме реализации и материализаџии постпамяти с помощью условной театрализаџии [28], интерактивной современной форме увековечения памяти о важнейших событиях военной истории [29]. В качестве одного из наиболее значимых источников формирования культурно-исторической памяти рассматриваются знания о прошиом, приобретаемые в системе среднего и высшего образования. В некоторых работах рассмотрена роль исторической реконструкции как актуальной и востребованной формы изучения истории, способствующей развитию интемлектуального и творческого потенџиала, реацизаџии проектной деятельности в системе образования и воспитания [30].

Систематизируя имеющиеся наработки по этой проблеме, отметим, что степень ее изученности с культурологических позиций явцяется пока недостаточной в силу масштабности и сложности Аанного феномена, динамичности процессов его трансформации, обусловленных амбивалентностью культуры постмодерна, влиянием современной социокумьтурной реальности, многообразием интеракций с соџиальными институтами и отдельными социальными субъектами. Пока слабо в культурологии реконструкции преАставлены теория и методология исслеАований, преАпомагающих культурологическую конџепџию времени как фактора генезиса и динамики культурных систем. Идеи исторического времени, используемые для создания образа прошлого и концепции множественной темпоральности, безусловно, требуют не только теоретического осмысления, но и получения полевых результатов, отражающих новое ощущение времени и его проявление в социокультурной практике сообществ и индивиАов. 
История культуры изучает происхождение, генезис, становление, эвоАюџию и развитие, в том чисме в пространственно-временных и соџиальных аспектах культур разцичных стран, регионов и народов. ОАнако мюбые фрагменты культурологических теорий или определенных культурных практик могут быть представлены в живой социальной атмосфере не только в случае культурно-исторической реконструкции. Но Аишь в том случае, если культурология поставит на службу инструментарий современной социологической науки. То обстоятельство, что многие гуманитарные науки в своем междисциплинарном взаимодействии активно используют соџиологические инструменты, усицивает инструментальную роль и значимость именно соџиологии. Поэтому мы илмюстрируем это обстоятельство на примере развития культуры реконструктивизма, используя фундаментальную базу соџиологического инструментария.

\section{Библиографический список}

1. Ярская В.Н. Методология диссертационного исследования: как защитить диссертацию. Полезно молодому ученому, соискателю ученой степени. М., 2011.

2. White L.A. The Concept of Cultural Systems: A Key to Understanding Tribes and Nations. N.-Y.: Columbia University Press, 1975.

3. Уайт Л. Избранное: Наука о культуре / пер. с англ. О.Р. Газизовой, П.В. Резвых. M., 2004.

4. Уайт Л. Избранное: эволюция культуры / сост. Л.А. Мостова; пер. с англ. О.Р. Газизовой, И.Ж. Кожановской. М., 2004.

5. Turner G. British Cultural Studies: An Introduction. Third ed. London: Routledge, 2003. URL: voorhees/dma135/Turner_British_Cultural_Studies_An_Introduction.pdf

6. Webster F. Cultural Studies and Sociology at, and After, the Closure of the Birmingham School // Cultural Studies. 2004. Vol. 18, issue 6. P. 847-862. URL: https://www.tandfonline. com/doi/abs/10.1080/0950238042000306891

7. Rojek C., Turner B. Decorative sociology: towards a critique of the cultural turn // The Sociological Review. 2000. November 1. Vol. 48, issue 4. P. 629-648. URL: https://journals. sagepub.com/doi/10.1111/ 1467-954X.00236

8. Bourdieu P. Distinction: A Social Critique of the Judgement of Taste. Cambridge, MA: Harvard University Press, 1984. URL: https://monoskop.org/images/e/e0/Pierre_Bourdieu_ Distinction_A_Social_Critique_of_the_Judgement_of_Taste_1984.pdf

9. Донская В.К., Широков О.Н. Зарубежная историография движения исторической реконструкции // Современные проблемы науки и образования. 2013. № 6. URL: http:// www. science-education.ru/ ru/article/ view?id=11449

10. Донская В.К., Широков О.Н. Историография движения исторической реконструкции на примере Волго-Вятского региона // Вестник Чувашского университета. 2012. № 4. URL: http://www.chuvsu.ru/images/ stories/nauka/ vestnik/vypusk/2012_4.pdf

11. Кадер A.M. Развитие движения исторической реконструкции на постсоветском пространстве: аналитический обзор литературы // Европейский журнал социальных наук. 2015. № 6. С. 237-242.

12. Ахиезер А.С. Россия: критика исторического опыта (Социокультурная динамика России). Т. I: От прошлого к будущему. Новосибирск, 1998.

13. Уйбо А.С. Проблема объективности реконструкций исторического прошлого: автореф. дис. ... канд. филос. наук (09.00.01). М., 1982. 
14. Лооне Э.Н. Современная философия истории. Таллинн, 1980.

15. Давыдов В.А. Эпистемологические и аксиологические аспекты реконструкции исторического прошлого // Вестник МГОУ. 2010. № 2. С. 18-23. URL: https://www.vestnikmgou.ru/Articles/Doc/3750

16. Ритиер Дж. Современные социологические теории. 5-е изд. / Сер.: Мастера психологии. СПб., 2002.

17. Костина А.В., Кожаринова А.Р. Актуальные проблемы современной культуры // Знание. Понимание. Умение. 2014. № 2. С. 390-394.

18. Шуб М.Л. Теоретико-методологические основания культурологического подхода к осмыслению прошлого // Вестник культуры и искусств. 2017. № 3 (51). С. 61-67.

19. Культура настоящего, прошлого и будущего в современных исследовательских парадигмах // Информационная эпоха: новые парадигмы культуры и образования / О.Н. Астафьева, Л.Б., Зубанова, Н.Б. Кириллова [и др.]; отв. ред. Н.Б. Кириллова. Екатеринбург, 2019.

20. Горбулева М.С. Феномен памяти и его роль в маргинальных субкультурах // Вестник ТГПУ (ТSPU Bulletin). 2013. № 11 (139). C. 182-187.

21. Тяглова М.A. Игра как способ конституирования сакрального начала в современных молодежных субкультурах (на примерах ролевого и реконструкторского движения): дис. ... канд. культурологии (24.00.01). Симферополь, 2017.

22. Ярская В.Н., Божок Н.С. Перспектива поколения: движение исторической реконструкции // Известия Саратовского университета. Нов. сер. Сер.: Социология. Политология. 2014. Т. 14, вып. 2. С. 19-26.

23. Тишков B.A. Усложняющее разнообразие: как его понимать и упорядочить // Культурная сложность современных наций / отв. ред. В.А. Тишков, Е.И. Филиппова. М., 2016.

24. Шаронова E.В. Движение исторической реконструкции в России: глубокая периодизация феномена // Научные школы. Молодежь в науке и культуре XXI века: материалы Междунар. науч.-творч. форума (науч. конф.). (1-2 нояб. 2018 г., Челябинск). Челябинск, 2018. URL: http://chgik.ru/sites/default/files/supportfile/mat_konf_molodezka2018.pdf

25. Кадер А.M. Организационные формы движения исторической реконструкции // Труды института бизнес-коммуникаций / под общ. ред. М.Э. Вильчинской-Бутенко. СПб., 2017. T. I. C. 172-174. URL: http://publish.sutd.ru/ docs/content/trudyIBK_2017.pdf

26. Байдуж М.И. (Ре)Конструируя историю: идеальные миры реконструкторов // Иллюзорные миры и медиумические практики в пространстве культуры: тезисы и материалы Всероссийской конференции с международным участием (Москва, РАНХиГС, 1-2 декабря 2017 г.) / сост. и ред. Н.В. Петров, О.Б. Христофорова. М., 2017. URL: http:// ruthenia.ru/folklore/2017_ImaginaryUniverses Proceedings_th.pdf

27. Поляков С.И. Мастер исторической реконструкции на сцене и в жизни // Этнографическое обозрение. 2017. № 4. C. 174-189. URL: articles/185478309

28. Гордин В.Э., Алушкин Л.М. Историческая реконструкция как форма театрализации и материализации ностальгии // Международный журнал исследований культуры. 2019. № 3(36). С. 140-153.

29. Медведев М.B. Роль военно-исторических реконструкций в увековечении памяти о Великой Отечественной войне в Ростовской области // Известия вузов. Северо-Кавказский регион. Общественные науки. 2018. № 4. С. 70-74.

30. Верещзагина И.М., Савинцева М.Е. Феномен исторической реконструкции в приобретении новых знаний о прошлом общества // Вестник Томского госуниверситета. История. 2019. № 59. С. 110-116. URL: http://journals.tsu.ru/history/ \&journal_page $=$ archive\&id $=1847$ \&article_id $=41175$ 